\title{
Strategi konservasi daerah tangkapan air bendung Ciliman Banten
}

\section{Conservation strategy for Ciliman dam catchment area, Banten}

\author{
Aditya Yumansyah ${ }^{\mathrm{a}}$, M. Yanuar J. Purwanto ${ }^{\mathrm{b}}$, Yudi Setiawan ${ }^{\mathrm{c}}$ \\ ${ }^{a}$ Program Studi Ilmu Pengelolaan Sumber Daya Alam dan Lingkungan, Sekolah Pascasarjana, Institut Pertanian Bogor, Kampus IPB \\ Baranangsiang Bogor, 16144, Indonesia [+62 251-8332779] \\ ${ }^{\text {b}}$ Departemen Teknik Sipil dan Lingkungan, Fakultas Teknologi Pertanian, Institut Pertanian Bogor, Kampus IPB Dramaga Bogor, \\ 16680, Indonesia [+62 251-8627225] \\ ${ }^{\mathrm{c}}$ Departemen Konservasi Sumberdaya Hutan dan Ekowisata, Fakultas Kehutanan, Institut Pertanian Bogor, Kampus IPB Darmaga \\ Bogor, 16680, Indonesia [+62 251-8621947]
}

\section{Article Info:}

Received: 27 - 07 - 2020

Accepted: 01 - 04 - 2021

Keywords:

Catchment area, Ciliman Dam, sustainability status, SWOT

Corresponding Author:

Aditya Yumansyah

Program Studi Ilmu Pengelolaan

Sumber Daya Alam dan

Lingkungan, Sekolah

Pascasarjana, Institut Pertanian

Bogor;

Tel. +6285697709951

Email:

adityayumansyah@gmail.com

\begin{abstract}
The catchment area (DTA) of the Ciliman Dam in Banten is a source of water for the Ciliman Dam, so it needs to be conserved so that Dam's reliability can be guaranteed. Changes in land use due to population growth in catchments have led to a decrease in forest area and increased land criticality. The forest area in the catchment is only $2.84 \%$ of the catchment area. The objectives of this study are (1) To identify the ecological, social, and economic conditions of the Ciliman Dam catchment area; (2) to know the status of sustainability in the Ciliman Dam catchment area; (3) to develop sustainable Ciliman Dam catchment area with conservation strategies. The methods used include descriptive analysis, image interpretation, multidimensional scaling (MDS) analysis, and SWOT analysis. The results of the analysis sustainability of the Ciliman Banten Dam catchment area showed entirely sustainable results with a value of $52.52 \%$, a stress value of $12.98 \%$, and an $R^{2}$ of $95.45 \%$. Based on the results of leverage analysis that shows the value of the attributes that are most sensitive to the sustainability of the catchment area, there are 7 attributes of the lever, among others in the ecological dimension there are 3 attributes namely land use, percentage of critical land, and forest area. On the economic dimension, there are 2 attributes, namely the number of cooperatives and the farmer exchange rate $(N T P)$, while on the social dimension there are 2 attributes, namely the unemployment rate and the level of education services. The SWOT analysis results for the internal factor analysis summary (IFAS) is 0.74, and the external factor analysis summary (EFAS) is 0.29. Based on the results above, the strategies that need to be implemented are to maintain the population growth rate to increase the rate of economic growth in the Ciliman Dam catchment, increasing public knowledge about the importance of sustainable catchments, and utilizing vegetation cover that is still high enough to increase value forest economy for the community.
\end{abstract}

How to cite (CSE Style $8^{\text {th }}$ Edition):

Yumansyah A, Purwanto MYJ, Setiawan Y. 2021. Strategi konservasi daerah tangkapan air bendung Ciliman Banten. JPSL 11(1): 152-164. http://dx.doi.org/10.29244/jpsl.11.1.152-164. 


\section{PENDAHULUAN}

Daerah Aliran Sungai (DAS) adalah suatu wilayah daratan yang secara topografik dibatasi punggungpunggung gunung dimana air hujan yang jatuh pada daerah tersebut akan ditampung oleh punggung gununggunung dan akan dialirkan melalui sungai-sungai kecil ke sungai utama. Wilayah daratan tersebut dinamakan daerah tangkapan air (DTA atau catchment area) yang merupakan kesatuan ekosistem yang utuh dari hulu sampai hilir yang terdiri atas unsur-unsur utama sumber daya alam yaitu tanah, vegetasi (hutan), air, dan sumber daya manusia sebagai pemanfaat sumber daya alam (Asdak, 2010). Penelitian ini khusus meneliti daerah tangkapan air (DTA) Bendung Ciliman, sehingga daerah penelitian dibatasi oleh DAS yang berada di atas Bendung Ciliman yang merupakan DAS Ciliman bagian hulu. Menurut Pawitan (2006), perubahan penggunaan lahan yang terjadi di daerah hulu DAS dipastikan akan mengakibatkan perubahan karakteristik hidrologi DAS. Perluasan kawasan dalam bentuk alih fungsi lahan, baik menjadi pemukiman maupun lahan pertanian dalam prosesnya seringkali tidak memerhatikan kaidah-kaidah konservasi tanah dan air. Oleh karena itu, pengelolaan daerah tangkapan air berkelanjutan diperlukan untuk mengurangi degradasi lahan yang semakin tinggi.

Daerah tangkapan air (DTA) Bendung Ciliman Banten merupakan sumber air bagi Bendung Ciliman, sehingga perlu dilakukan konservasi sehingga keandalan air bendung dapat terjamin. Penelitian ini khusus meneliti daerah tangkapan air (DTA) Bendung Ciliman, sehingga daerah penelitian dibatasi oleh DAS yang berada di atas Bendung Ciliman yang merupakan DAS Ciliman bagian hulu. Perubahan tata guna lahan akibat pertumbuhan penduduk di DTA telah menyebabkan menurunnya luas hutan dan meningkatnya kekritisan lahan. Perluasan kawasan dalam bentuk alih fungsi lahan, baik menjadi pemukiman maupun lahan pertanian dalam prosesnya seringkali tidak memerhatikan kaidah-kaidah konservasi tanah dan air. Perubahan penggunaan lahan di lokasi penelitian diakibatkan oleh pertumbuhan penduduk yang didorong oleh berbagai kegiatan ekonomi untuk memenuhi kebutuhan manusia seperti pemukiman, pertanian, perkebunan, industri, dan lain-lain. Perubahan tata guna lahan akibat pertumbuhan penduduk tersebut telah menyebabkan menurunnya luas hutan dan meningkatnya kekritisan lahan yang sebagian besar adalah potensial kritis (66.6\%), lahan agak kritis (10.2\%), lahan kritis (6.3\%), lahan sangat kritis (1.4\%), dan lahan tidak kritis yang hanya sebesar 15.5\% (Dinas Sumberdaya Air dan Pemukiman Provinsi Banten, 2016). Tutupan lahan DAS Ciliman didominasi oleh pertanian lahan kering campur semak/kebun campur, pertanian lahan kering, hutan tanaman, dan sawah. Di bagian hulu didominasi oleh pertanian lahan campur semak/kebun campur, sebagian kecil hutan dataran rendah, dan perkebunan kelapa sawit (Badan Lingkungan Hidup Daerah Provinsi Banten, 2015). Degradasi pada DTA tersebut mengakibatkan terjadinya berbagai bencana seperti kekeringan dan banjir, tanah longsor, dan lahan kritis yang semakin meluas. Pengurangan tutupan lahan sebagai penahan laju limpasan tersebut juga akan mengakibatkan tingginya sedimentasi dan erosi yang akan mendangkalkan daerah-daerah tangkapan air di bawahnya. Oleh karena itu, penelitian ini bertujuan untuk merumuskan strategi konservasi daerah tangkapan air Bendung Ciliman yang berkelanjutan dengan menggunakan metode SWOT.

\section{METODE}

\section{Lokasi dan Waktu Penelitian}

Penelitian ini berlokasi di Bendung Ciliman, Kabupaten Lebak, Banten. Lokasi penelitian berupa daerah tangkapan air Bendung Ciliman yang merupakan bagian dari daerah aliran sungai (DAS) Ciliman bagian hulu. DTA Bendung Ciliman terdiri dari 3 kecamatan yaitu Kecamatan Banjarsari, Kecamatan Cirinten, dan Kecamatan Gunung Kencana. Penelitian dilakukan pada bulan Januari 2019 sampai Januari 2020. 


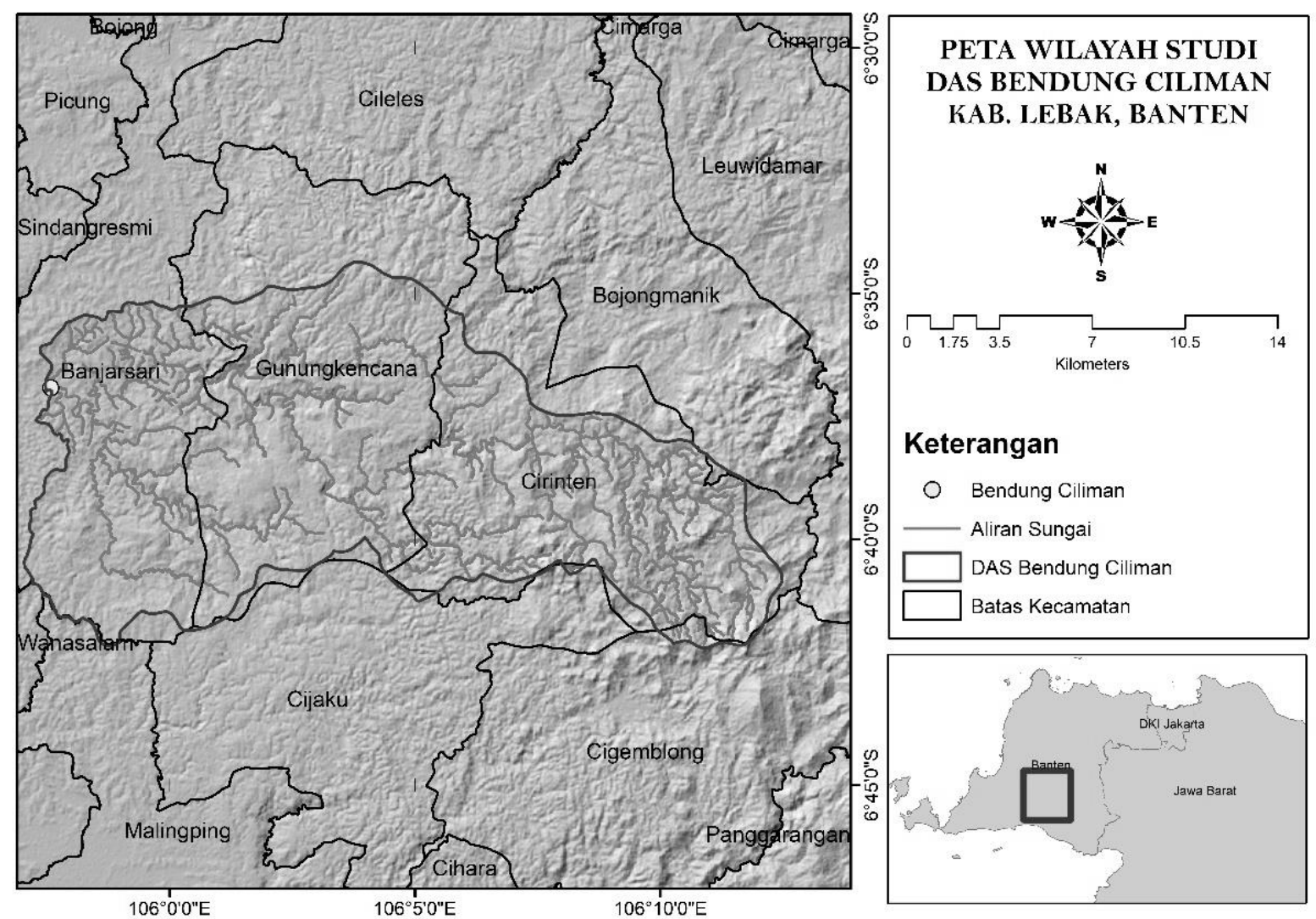

Gambar 1 Lokasi daerah tangkapan air (DTA) Bendung Ciliman

\section{Metode Pengumpulan Data}

Jenis data yang digunakan dalam penelitian ini adalah data primer dan sekunder. Teknik pengumpulan data yang digunakan dalam penelitian ini antara lain menganalisis data primer dengan wawancara dengan dinas terkait. Data sekunder didapat dari beberapa instansi terkait seperti BPDAS, Dinas PU, BPS Provinsi Banten, studi pustaka, peta, dan dokumen lainnya.

\section{Metode Analisis Data}

\section{Analisis Deskriptif}

Analisis deskriptif dilakukan dengan mengumpulkan, merangkum, serta menginterpretasikan data-data berbagai kondisi lapangan yang diperoleh melalui wawancara dan olahan data-data sekunder. Analisis deskriptif digunakan untuk menganalisis kondisi ekologi, ekonomi, dan sosial DTA Bendung Ciliman.

\section{Klasifikasi Tutupan dan Penggunaan Lahan}

Klasifikasi tutupan lahan pada penelitian ini menggunakan data sekunder tutupan dan penggunaan lahan DAS Ciliman tahun 2016. Klasifikasi yang dilakukan menggunakan software ArcGIS dengan metode klasifikasi terbimbing. Klasifikasi terbimbing merupakan metode yang dipantau dan dikendalikan sebagian besar oleh pengguna. Intervensi pengguna dimulai sejak penentuan area hingga tahap klasifikasinya. Penilaian indikator pengelolaan lahan (PL) dalam penelitian ini adalah tingkat pengelolaan lahan dan vegetasi di DAS, merupakan perkalian antara faktor penutupan lahan/pengelolaan tanaman (C) dengan faktor praktik konservasi tanah/pengelolaan lahan (P) (Permenhut no. P.61/Menhut-II/2014). Kriteria penggunaan lahan dan perhitungannya disajikan dalam Tabel 1 . 
Tabel 1 Kriteria dan penilaian penggunaan lahan

\begin{tabular}{ccc}
\hline Kriteria & Sub Kriteria & Parameter \\
\hline \multirow{3}{*}{ Penggunaan Lahan (PL) } & $\mathrm{PL}=\mathrm{C} \times \mathrm{P}$ & $\mathrm{PL} \leq 0.3$ (buruk) \\
& $\mathrm{C} \times \mathrm{P}=\frac{\sum(A i x \text { CPi) }}{A}$ & $0.3<\mathrm{PL} \leq 0.5$ (sedang) \\
& $\mathrm{PL} \geq 0.5$ (baik) \\
\hline
\end{tabular}

Keterangan: $\mathrm{C}=$ faktor penutupan lahan/pengelolaan tanaman, $\mathrm{P}=$ faktor praktik konservasi tanah/pengelolaan lahan, $\mathrm{PL}=$ indikator pengelolaan lahan, $\mathrm{CPi}=\mathrm{C} \times \mathrm{P}$ lahan $\mathrm{ke} \mathrm{i}, \mathrm{Ai}=$ luas lahan $\mathrm{ke} \mathrm{i}, \mathrm{A}=$ luas lahan total Sumber: Permenhut no. P.61/Menhut-II/2014

\section{Analisis Koefisien Rezim Aliran (KRA)}

Kriteria dan indikator kinerja DAS berupa perhitungan koefisien rezim aliran (KRA) dan koefisien aliran permukaan mengacu pada Peraturan Menteri Kehutanan nomor P.61/Menhut-II/2014 tentang Monitoring dan Evaluasi Pengelolaan Daerah Aliran Sungai (Tabel 2).

Tabel 2 Kriteria kinerja DAS

\begin{tabular}{lcc}
\hline Kriteria & Sub Kriteria & Parameter \\
\hline KRA & KRA $=\frac{\text { Qmaks }}{\text { Qmin }}$ & KRA $\leq 20$ (sangat rendah) \\
& & $20<$ KRA $\leq 50$ (rendah) \\
& & $50<$ KRA $\leq 80$ (sedang) \\
& $80<$ KRA $\leq 110$ (tinggi) \\
& & KRA $\geq 110$ (sangat tinggi) \\
\hline
\end{tabular}

Keterangan: $\mathrm{KRA}=$ koefisien rezim aliran, $\mathrm{Qmaks}=$ debit maksimum, $\mathrm{Qmin}=$ debit minimum

\section{Analisis Keberlanjutan Daerah Tangkapan Air}

Analisis keberlanjutan daerah tangkapan air Bendung Ciliman dilakukan melalui pendekatan "multi dimensional scaling" (MDS) dengan menggunakan analisis Rap-DTA (Rapid Appraisal Sustainability Index for Daerah Tangkapan Air) yang merupakan modifikasi dari RAPFISH (The Rapid Appraissal of the Status of Fisheries). Rap-DTA merupakan Rapfish dengan modifikasi pada atribut-atribut yang sesuai dengan kondisi dan karakteristik DTA Bendung Ciliman. Tahapan analisis MDS secara ringkas dapat dilihat pada Gambar 2.

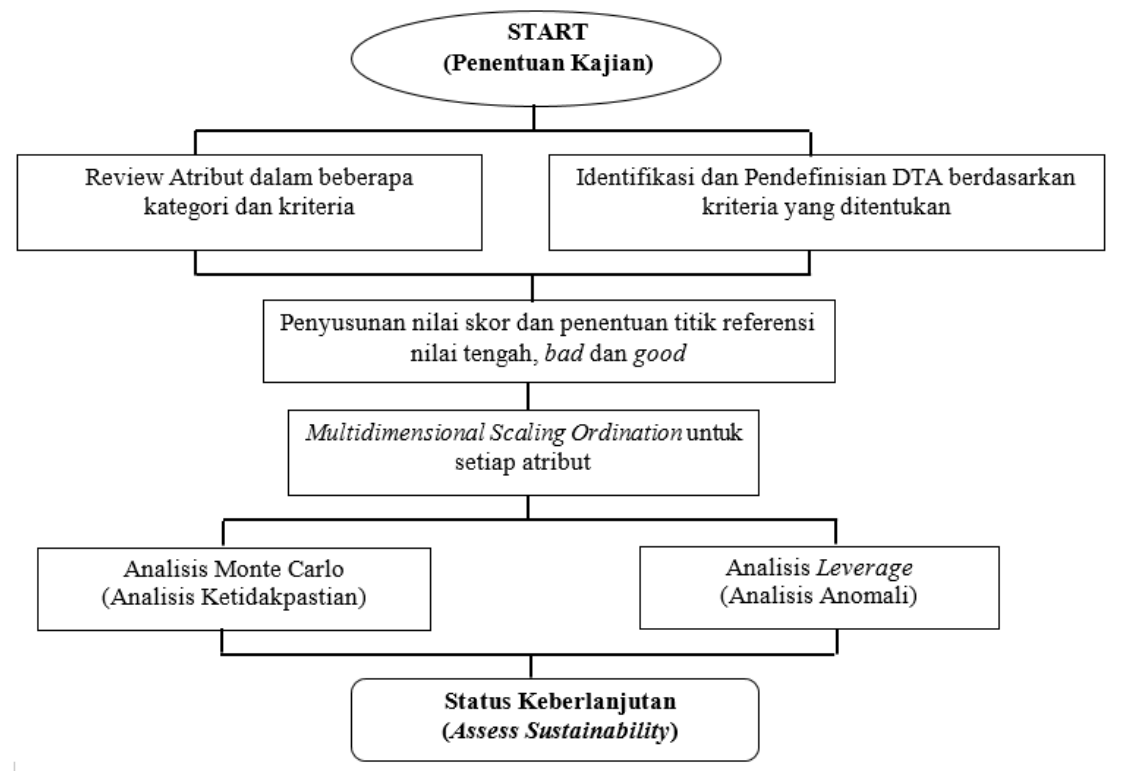

Gambar 1 Tahapan analisis keberlanjutan multi-dimensional scaling (MDS) 
Dimensi yang digunakan pada MDS terdiri atas dimensi ekologi, ekonomi, dan sosial. Dimensi ekologi terdiri atas (1) persentase penutupan vegetasi; (2) luas hutan; (3) penggunaan lahan; (4) koefisien rezim aliran; (5) persentase lahan kritis; (6) alih fungsi lahan. Dimensi ekonomi terdiri atas (1) tingkat pendapatan; (2) tingkat kesejahteraan penduduk; (3) jumlah koperasi; (4) nilai tukar petani (NTP); (5) dana desa. Dimensi sosial terdiri atas (1) laju pertumbuhan penduduk; (2) tekanan penduduk terhadap DTA; (3) tingkat pengangguran; (4) tingkat layanan Pendidikan; (5) program diklat. Skala indeks keberlanjutan dari sistem yang dikaji mempunyai nilai $0 \%$ hingga 100\% seperti Tabel 3. Penilaian terhadap keseluruhan atribut dari masingmasing dimensi keberlanjutan tersebut dikategorikan ke dalam baik, cukup, kurang, dan buruk. Hasil penilaian masing-masing dimensi keberlanjutan disajikan dalam diagram layang-layang dengan menggunakan software Rapfish yang dimodifikasi menjadi Rap-DTA.

Tabel 3 Kategori indeks dan status keberlanjutan

\begin{tabular}{ccc}
\hline Nilai Indeks & Kategori & Keterangan \\
\hline $0-25$ & Buruk & Tidak berkelanjutan \\
$26-50$ & Kurang & Kurang berkelanjutan \\
$51-75$ & Cukup & Cukup berkelanjutan \\
$76-100$ & Baik & Berkelanjutan \\
\hline
\end{tabular}

Sumber: Kavanagh, 2001

\section{Analisis SWOT (strengths, weaknesses, opportunities, threaths)}

Analisis SWOT dilakukan untuk menyusun strategi konservasi daerah tangkapan air yang baik berdasarkan hasil analisis MDS. Hasil analisis MDS yang berupa atribut ditentukan komponen internal dan eksternalnya kemudian dievaluasi dengan menggunakan analisis internal factor analysis summary (IFAS) dan external factor analysis summary (EFAS). Penyusunan strategi dengan pendekatan formulasi strategi matriks SWOT menggambarkan peluang dan ancaman eksternal yang dihadapi dapat disesuaikan dengan kekuatan dan kelemahan yang dimiliki (Rangkuti, 2014). Empat strategi utama yang dapat dirumuskan, yaitu: 1) Strategi S-O pada kuadran I, yaitu "pemanfaatan" keunggulan kompetitif. Strategi ini dilakukan dengan memanfaatkan kekuatan untuk merebut dan memanfaatkan peluang; 2) Strategi S-T pada kuadran II, yaitu "mendayagunakan" kekuatan. Strategi ini dijalankan dengan menggunakan kekuatan untuk mengatasi ancaman; 3) Strategi W-T pada kuadran III, yaitu "mengantisipasi" ancaman dan menutup kelemahan. Strategi ini bersifat defensif yang berusaha meminimalkan kelemahan dan menghindari ancaman; 4) Strategi W-O pada kuadran IV, yaitu "minimasi" kelemahan (diterapkan berdasarkan pemanfaatan peluang dengan cara meminimalkan kelemahan).

\section{HASIL DAN PEMBAHASAN}

\section{Gambaran Umum Lokasi Penelitian}

Daerah tangkapan air (DTA) Bendung Ciliman merupakan bagian DAS Ciliman hulu yang terdiri atas 3 Kecamatan dengan luas 28726.96 ha. DTA tersebut memiliki jumlah penduduk sebesar 104327 jiwa dengan jumlah penduduk miskin sebesar 23583 jiwa dan jumlah pengangguran sebesar 24493 jiwa. Jumlah koperasi yang ada di lokasi penelitian hanya sebanyak 8 koperasi sedangkan jumlah sekolah dari tingkat SD sampai SMA/SMK masih cukup banyak yaitu sebesar 118 sekolah (BPS Kabupaten Lebak, 2017).

Tutupan dan penggunaan lahan di DTA Bendung Ciliman terdiri atas area pemukiman (1.75\%), area terisi air $(0.49 \%)$, gedung $(0.01 \%)$, hutan $(3.41 \%)$, perkebunan $(49.87 \%)$, rawa $(0.01 \%)$, rumput/tanah kosong (0.02\%), sawah irigasi (7.03\%), sawah tadah hujan (2.32\%), semak belukar (28.99\%), tanah berbatu (0.001\%), dan tegalan ladang (6.10\%). DTA memiliki luas hutan yang masih sangat rendah hanya sebesar $3.41 \%$. Lahan kritis yang terdapat di daerah tangkapan air Bendung Ciliman yaitu seluas 1 017.62 Ha (Dinas Sumberdaya 
Air dan Pemukiman Provinsi Banten, 2016). Secara rinci klasifikasi tutupan dan penggunaan lahan disajikan pada Tabel 4.

Tabel 4 Persentase penggunaan lahan DTA Bendung Ciliman

\begin{tabular}{clcc}
\hline No & \multicolumn{1}{c}{ Penggunaan Lahan } & Luas (ha) & Persentase (\%) \\
\hline 1 & Area Pemukiman & 420.28 & 1.75 \\
2 & Area Terisi Air & 116.77 & 0.49 \\
3 & Gedung & 1.30 & 0.01 \\
4 & Hutan & 816.79 & 3.41 \\
5 & Perkebunan & 11945.52 & 49.87 \\
6 & Rawa & 1.91 & 0.01 \\
7 & Rumput/Tanah Kosong & 4.66 & 0.02 \\
8 & Sawah Irigasi & 1684.10 & 7.03 \\
9 & Sawah Tadah Hujan & 556.40 & 2.32 \\
10 & Semak Belukar & 6944.40 & 28.99 \\
11 & Tanah Berbatu & 0.89 & 0.00 \\
12 & Tegalan/Ladang & 1460.71 & 6.10 \\
\hline \multicolumn{1}{r}{ Jumlah } & 23953.73 & 100 \\
\hline
\end{tabular}

Sumber: Dinas PUPR Provinsi Banten Tahun, 2016

\section{Penilaian Indeks dan Status Keberlanjutan}

Analisis keberlanjutan menggunakan multi dimensional scaling (MDS) berdasarkan Rapid Apprisial for DTA (Rap-DTA) setiap dimensi menunujukkan nilai ekologi $44.38 \%$ (kurang berkelanjutan); ekonomi $48.21 \%$ (kurang berkelanjutan), sosial 53.48\% (cukup berkelanjutan) (Gambar 3). Hasil analisis Rapfish dengan pendekatan Multidimensional Scaling (MDS) menunjukkan bahwa daerah tangkapan air (DTA) Bendung Ciliman Banten memiliki nilai indeks keberlanjutan sebesar 52.52\% dan dikategorikan cukup berkelanjutan. Nilai indeks keberlanjutan tersebut dihasilkan berdasarkan penilaian terhadap atribut yang tercakup dalam tiga dimensi keberlanjutan yang terdiri dari 16 atribut (Gambar 4). Menurut Zagonari (2008) dan William et al. (2008), berdasarkan status keberlanjutannya, pengambilan keputusan untuk mempertahankan atau mengembangkan status tersebut dapat dilakukan secara objektif. Pengembangan status keberlanjutan difokuskan pada perbaikan keadaan atribut-atribut pengungkit keberlanjutan.

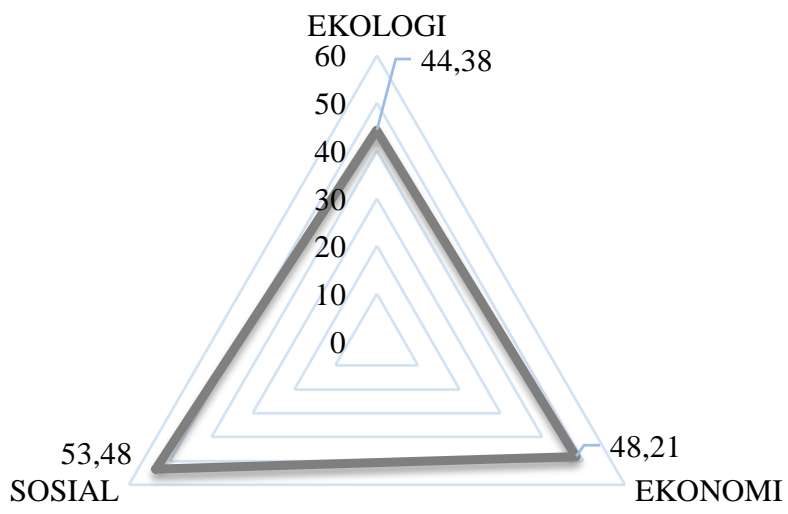

Gambar 3 Indeks dan status keberlanjutan tiap dimensi DTA 


\section{Analisis Leverage}

Analisis leverage digunakan untuk melihat atribut sensitif sebagai atribut pengungkit yang berpengaruh terhadap keberlanjutan daerah tangkapan air Bendung Ciliman. Atribut yang diperoleh dari hasil analisis, ditentukan dengan cara memilah atribut yang memiliki nilai perubahan RMS (root mean square) lebih dari setengah skala nilai pada sumbu $\mathrm{x}$.

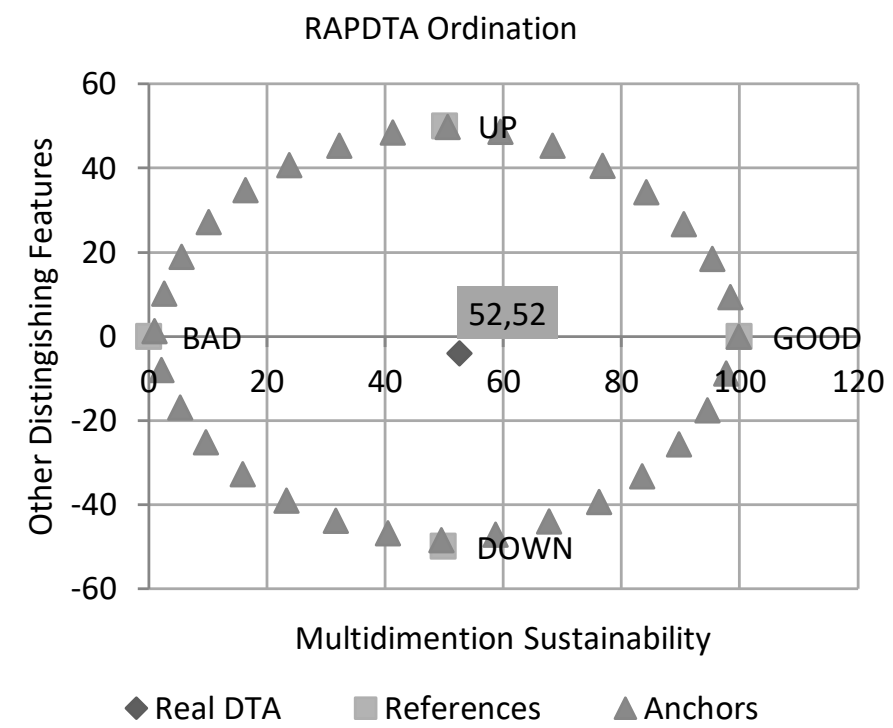

Gambar 4 Indeks dan status keberlanjutan multidimensi

Hasil analisis leverage dimensi ekologi (Gambar 5), menunjukkan terdapat tiga atribut sensitif berpengaruh terhadap daerah tangkapan air yaitu (1) penggunaan lahan; (2) persentase lahan kritis; (3) luas hutan.

\section{Leverage of Attributes}

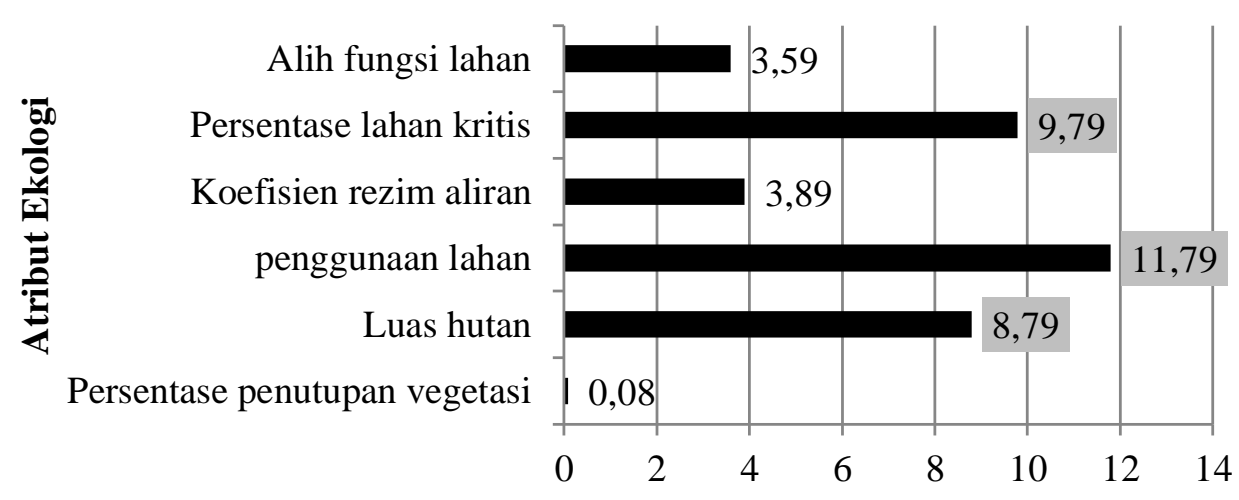

\section{Root Mean Square Change in Ordination when Selected \\ Attribute Removed \\ (on Sustainability scale 0 to 100)}

Gambar 5 Hasil analisis leverage dimensi ekologi

Sementara itu, hasil analisis leverage dimensi ekonomi (Gambar 6), menunjukkan terdapat dua atribut sensitif berpengaruh terhadap daerah tangkapan air yaitu (1) jumlah koperasi; (2) nilai tukar petani (NTP). 


\section{Leverage of Attributes}

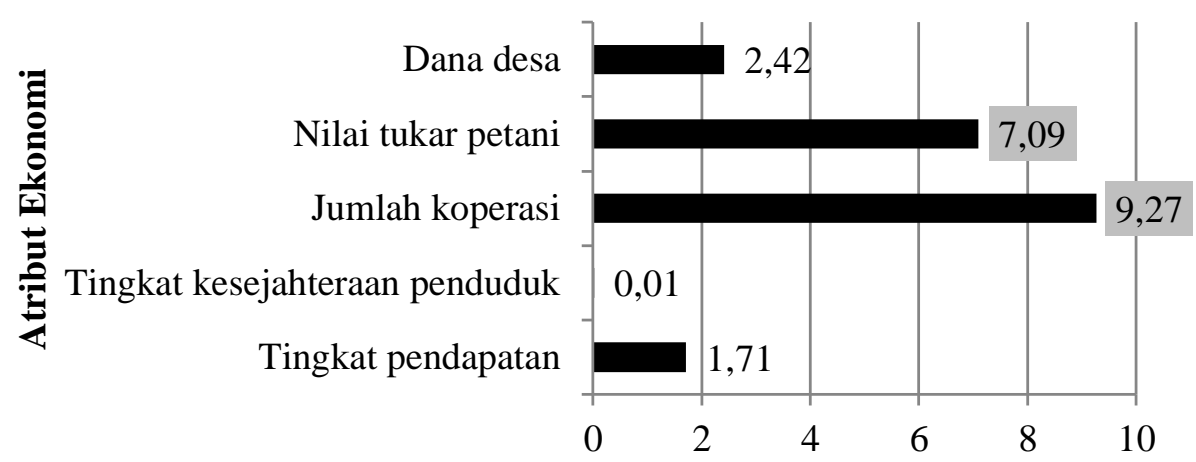

\section{Root Mean Square Change in Ordination when Selected Attribute Removed...}

Gambar 6 Hasil analisis leverage dimensi ekonomi

Hasil analisis leverage dimensi sosial (Gambar 7), menunjukkan terdapat dua atribut sensitif berpengaruh terhadap daerah tangkapan air yaitu (1) tingkat pengangguran; (2) tingkat layanan pendidikan.

\section{Leverage of Attributes}

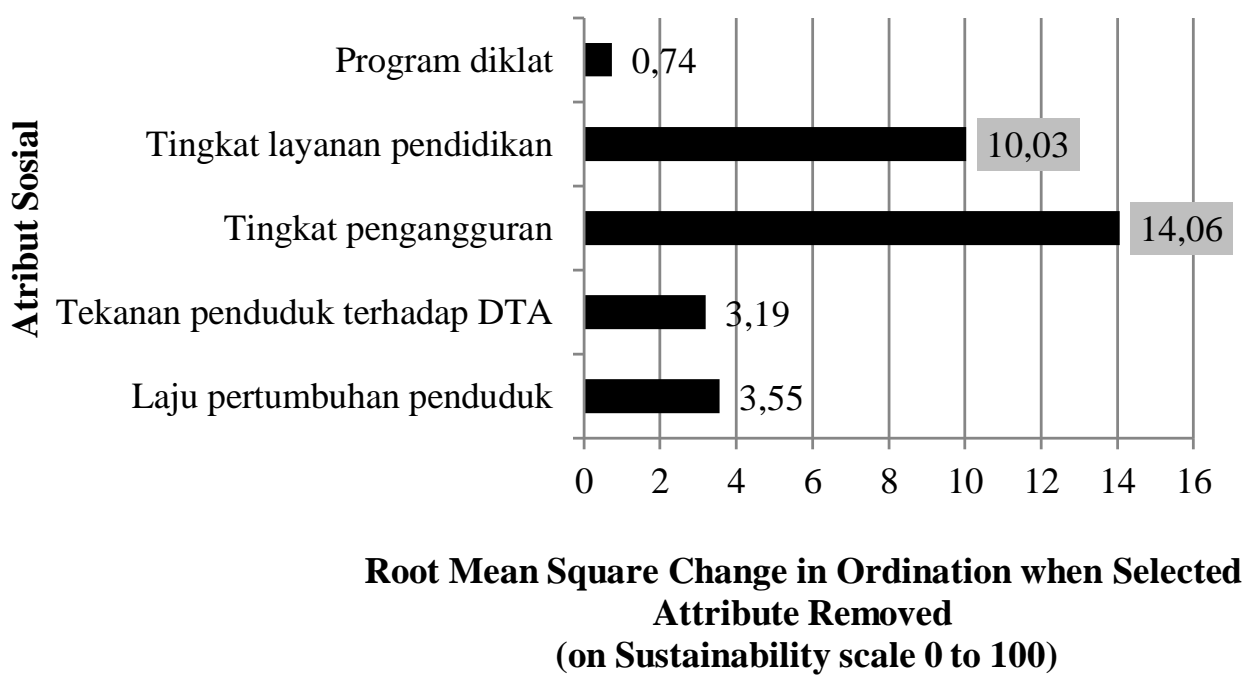

Gambar 7 Hasil analisis leverage dimensi sosial

\section{Analisis Monte Carlo}

Analisis Monte Carlo dilakukan untuk menunjukkan kestabilan dari nilai indeks keberlanjutan daerah tangkapan air yang dihasilkan. Analisis Monte Carlo untuk memperhitungkan ketidakpastian pada selang kepercayaan 95\%. Hasil analisis dibandingkan dengan hasil analisis MDS. Jika nilai selisih kedua analisis tersebut $<5 \%$, maka hasil analisis memadai (Tabel 5). Perbedaan nilai yang kecil menunjukkan: (1) kesalahan pembuatan skor setiap atribut relatif kecil, (2) pemberian skor akibat perbedaan opini relatif kecil, (3) analisis MDS yang berulang relatif stabil, dan (4) kesalahan data dan data yang hilang dapat dihindari. Parameter uji statistik menunjukkan metode Rapfish cukup baik sebagai salah satu alat evaluasi keberlanjutan daerah tangkapan air secara kuantitatif dan cepat (rapid appraisal). 
Tabel 5 Hasil analisis Monte Carlo nilai Rapfish pada selang kepercayaan 95\%

\begin{tabular}{lccc}
\hline Dimensi & MDS (\%) & Monte Carlo $(\%)$ & Selisih (\%) \\
\hline Ekologi & 44.38 & 44.77 & 0.39 \\
Ekonomi & 48.21 & 47.97 & 0.24 \\
Sosial & 53.48 & 52.67 & 0.81 \\
\hline Multidimensi & 52.52 & 52.01 & 0.51 \\
\hline
\end{tabular}

\section{Penilaian Ketepatan (goodness of fit)}

Ketepatan analisis Multi Dimensional Scaling (MDS) ditentukan oleh nilai S-Stress. Nilai S-Stress analisis MDS masing-masing dimensi dan rataannya memiliki nilai $<0.25$ di mana semakin kecil nilai stress maka output model analisis MDS semakin baik. Koefisien determinasi $\left(\mathrm{R}^{2}\right)$ setiap dimensi dan rataan memiliki nilai yang tinggi. Hal ini ditunjukkan dengan besaran nilai mendekati 1. Berdasarkan kedua parameter statistik tersebut (Tabel 6) dapat disimpulkan bahwa seluruh atribut yang digunakan dapat menggambarkan keberlanjutan daerah tangkapan air (DTA) Bendung Ciliman Banten.

Tabel 6 Parameter statistik (goodness of fit) analisis indeks keberlanjutan

\begin{tabular}{clcccc}
\hline \multirow{2}{*}{ No } & \multicolumn{1}{c}{ Dimensi } & \multicolumn{4}{c}{ Nilai Statistik } \\
\cline { 3 - 6 } & \multicolumn{1}{c}{ Keberlanjutan } & Stress & Persentase $(\%)$ & $\mathrm{R}^{2}$ & Persentase (\%) \\
\hline 1 & Ekologi & 0.14 & 14 & 0.93 & 93 \\
2 & Ekonomi & 0.15 & 15 & 0.93 & 93 \\
3 & Sosial & 0.15 & 15 & 0.92 & 92 \\
\hline 4 & Multidimensi & 0.12 & 12 & 0.95 & 95 \\
\hline
\end{tabular}

\section{Analisis Strengths, Weaknesses, Opportunities, Threats (SWOT)}

\section{Analisis IFAS - EFAS}

Strategi konservasi DTA Bendung Ciliman, Kabupaten Lebak, Banten dianalisis menggunakan SWOT. Analisis MDS menghasilkan 16 atribut yang akan digunakan untuk menganalisis strategi konservasi menggunakan SWOT. Hasil analisis MDS yang berupa atribut ditentukan komponen internal dan eksternalnya kemudian dievaluasi. Secara rinci evaluasi atas komponen internal dan eksternalnya dijabarkan pada (Tabel 7). Berdasarkan hasil analisis matriks evaluasi komponen internal dan komponen eksternal, didapatkan hasil akhir analisis internal factor analysis summary (IFAS) yaitu kekuatan dikurangi kelemahan menjadi sebesar 0.74 dan external factor analysis summary (EFAS) yaitu pengurangan peluang dikurangi ancaman menjadi sebesar 0.29. Hasil analisis kuadran menunjukkan posisinya berada pada kuadran I (strategi Strengths Opportunities) yaitu strategi progresif dan berusaha memanfaatkan kekuatan dan peluang (Rangkuti, 2014). Posisi kuadran strategi ditampilkan seperti pada Gambar 8.

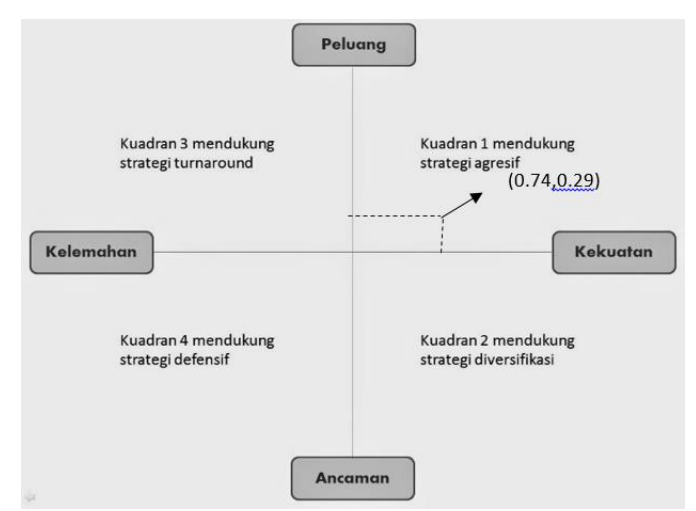


Tabel 7 Matriks evaluasi kondisi internal dan eksternal

\begin{tabular}{|c|c|c|c|c|c|c|c|c|c|c|c|}
\hline \multirow{2}{*}{ No } & \multirow{2}{*}{$\begin{array}{c}\text { Komponen Internal dan } \\
\text { Eksternal }\end{array}$} & \multirow{2}{*}{ Pengaruh $^{1)}$} & \multirow{2}{*}{ Bobot $^{2)}$} & \multicolumn{2}{|c|}{$S^{3)}$} & \multicolumn{2}{|c|}{$\mathrm{W}^{4)}$} & \multicolumn{2}{|c|}{$\mathrm{O}^{5)}$} & \multicolumn{2}{|c|}{$\mathrm{T}^{6)}$} \\
\hline & & & & $\mathrm{R}^{7)}$ & $\mathrm{N}^{8)}$ & $\mathrm{R}$ & $\mathrm{N}$ & $\mathrm{R}$ & $\mathrm{N}$ & $\mathrm{R}$ & $\mathrm{N}$ \\
\hline A & Kekuatan (Strenghts) & & & & & & & & & & \\
\hline 1 & Penutupan vegetasi & 2 & 0.18 & 3 & 0.55 & & & & & & \\
\hline 2 & Koefisien rezim aliran & 3 & 0.27 & 2 & 0.55 & & & & & & \\
\hline 3 & Tingkat pendapatan & 3 & 0.27 & 2 & 0.55 & & & & & & \\
\hline 4 & Pertumbuhan penduduk & 3 & 0.27 & 3 & 0.82 & & & & & & \\
\hline \multicolumn{2}{|c|}{ Total } & & & & 2.45 & & & & & & \\
\hline B & Kelemahan (Weaknesses) & & & & & & & & & & \\
\hline 5 & Luas hutan & 4 & 0.29 & & & 1 & 0.29 & & & & \\
\hline 6 & Penggunaan lahan & 4 & 0.29 & & & 1 & 0.29 & & & & \\
\hline 7 & Lahan kritis & 4 & 0.29 & & & 3 & 0.86 & & & & \\
\hline 8 & Kesejahteraan penduduk & 2 & 0.14 & & & 2 & 0.29 & & & & \\
\hline \multicolumn{2}{|l|}{ Total } & & & & & & 1.71 & & & & \\
\hline $\mathrm{C}$ & Peluang (Opportunities) & & & & & & & & & & \\
\hline 9 & Jumlah koperasi & 4 & 0.31 & & & & & 1 & 0.31 & & \\
\hline 10 & Dana desa & 3 & 0.23 & & & & & 3 & 0.69 & & \\
\hline 11 & Layanan pendidikan & 4 & 0.31 & & & & & 3 & 0.92 & & \\
\hline 12 & Program diklat & 2 & 0.15 & & & & & 1 & 0.15 & & \\
\hline \multicolumn{2}{|c|}{ Total } & & & & & & & & 2.08 & & \\
\hline $\mathrm{D}$ & Ancaman (Threaths) & & & & & & & & & & \\
\hline 13 & Alih fungsi lahan & 3 & 0.21 & & & & & & & 1 & 0.21 \\
\hline 14 & Nilai tukar petani & 4 & 0.29 & & & & & & & 3 & 0.86 \\
\hline 15 & Tekanan terhadap DTA & 3 & 0.21 & & & & & & & 2 & 0.43 \\
\hline 16 & Tingkat pengangguran & 4 & 0.29 & & & & & & & 1 & 0.29 \\
\hline Total & & & & & & & & & & & 1.79 \\
\hline
\end{tabular}

Keterangan: ${ }^{1}$ Skala mulai dari 1 (tidak penting), 2 (cukup penting), 3 (penting) dan 4 (sangat penting); ${ }^{2}$ nilai pengaruh dibagi dengan jumlah total nilai pengaruh; ${ }^{3)}$ strengths (kekuatan); ${ }^{4)}$ weaknesses (kelemahan); ${ }^{5)}$ opportunities (peluang); ${ }^{6}$ threats (ancaman); ${ }^{7} \mathrm{r}$ (rating): nilai positif (+) untuk kekuatan dan peluang, nilai negatif (-) yang menunjukkan kelemahan dan ancaman dengan skala mulai dari 1 (tidak baik), 2 (cukup baik), 3 (baik) dan 4 (sangat baik) berdasarkan kondisi yang ada; ${ }^{8}$ n (nilai total): bobot $\mathrm{x}$ rating

\section{Strategi Konservasi Daerah Tangkapan Air (DTA) Bendung Ciliman Banten}

Berdasarkan hasil analisis IFAS-EFAS di atas dihasilkan strategi pilihan untuk menunjang keberlanjutan DTA Bendung Ciliman. Pilihan strategi tersebut dijabarkan dalam matriks Tabel 8. Komponen-komponen kekuatan dan peluang dalam konservasi DTA yang perlu dimanfaatkan yaitu laju pertumbuhan, penduduk persentase tutupan vegetasi, dana desa, dan tingkat layanan pendidikan. Penentuan prioritas strategi dilakukan melalui 2 tahap yaitu dilihat dari sensitifitas analisis MDS dan hasil analisis IFAS-EFAS SWOT. Hasil strategi SWOT menunjukkan prioritas strategi disesuaikan dengan atribut leverage dalam MDS dan analisis IFASEFAS menghasilkan strategi dengan prioritas sebagai berikut:

1. Laju pertumbuhan penduduk yang rendah dapat mengalihkan kebutuhan ekonomi pada tingkat layanan pendidikan, jumlah koperasi, program diklat, dan dana desa. 
2. Tutupan vegetasi di DTA Bendung Ciliman cukup tinggi dapat dimanfaatkan oleh masyarakat sekitar hutan untuk membentuk koperasi yang dapat meningkatkan nilai ekonomi hutan. Nilai ekonomi hutan yang dapat dimanfaatkan antara lain untuk produksi biomassa, sarana rekreasi, pemanfaatan tumbuhan obat, dll (Munasinghe, 1993).

Tabel 8 Matriks pilihan strategi SWOT

\begin{tabular}{|c|c|c|c|c|c|c|c|c|}
\hline \multirow{2}{*}{ 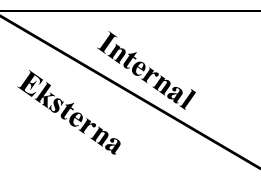 } & \multicolumn{4}{|c|}{ Kekuatan (S) } & \multicolumn{4}{|c|}{ Kelemahan (W) } \\
\hline & $\begin{array}{l}\text { Pertumbuhan } \\
\text { Penduduk }\end{array}$ & $\begin{array}{l}\text { Tutupan } \\
\text { Vegetasi }\end{array}$ & $\begin{array}{l}\text { Koefisien } \\
\text { Rejim } \\
\text { Aliran }\end{array}$ & $\begin{array}{l}\text { Tingkat } \\
\text { Pendapatan }\end{array}$ & $\begin{array}{l}\text { Luas } \\
\text { Hutan }^{1)}\end{array}$ & $\begin{array}{l}\text { Penggunaan } \\
\text { Lahan }^{1)}\end{array}$ & $\begin{array}{l}\text { Lahan } \\
\text { Kritis }{ }^{1)}\end{array}$ & $\begin{array}{l}\text { Kesejahteraan } \\
\text { Penduduk }\end{array}$ \\
\hline 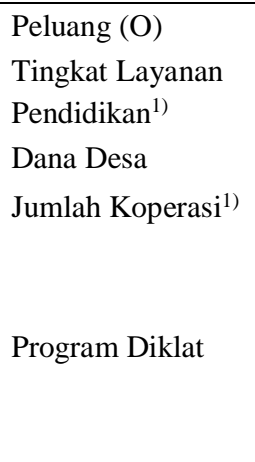 & \multicolumn{4}{|c|}{$\begin{array}{l}\text { - Laju pertumbuhan penduduk yang rendah } \\
\text { dapat mengalihkan kebutuhan ekonomi pada } \\
\text { tingkat layanan pendidikan, jumlah koperasi, } \\
\text { program diklat, dan dana desa. } \\
\text { - Tutupan vegetasi di DTA Bendung Ciliman } \\
\text { cukup tinggi dapat dimanfaatkan oleh masyarakat } \\
\text { sekitar hutan untuk membentuk koperasi yang } \\
\text { dapat meningkatkan nilai ekonomi hutan. }\end{array}$} & \multicolumn{4}{|c|}{$\begin{array}{l}\text { - Memanfaatkan tingkat layanan pendidikan yang } \\
\text { baik untuk meningkatkan pengetahuan } \\
\text { masyarakat agar luas hutan meningkat dan lahan } \\
\text { kritis menurun } \\
\text { - Dana desa yang cukup tinggi dapat dimanfaatkan } \\
\text { untuk meningkatkan luas hutan, menurunkan } \\
\text { lahan kritis, meningkatkan kesejahteraan } \\
\text { penduduk } \\
\text { - Program diklat dapat meningkatkan pengetahuan } \\
\text { masyarakat dalam pengelolaan hutan dan lahan } \\
\text { yang berkelanjutan }\end{array}$} \\
\hline $\begin{array}{l}\text { Ancaman (T) } \\
\text { Alih Fungsi Lahan } \\
\text { Nilai Tukar } \\
\text { Petani }^{1)} \\
\text { Tekanan } \\
\text { Penduduk } \\
\text { Terhadap DTA } \\
\text { Tingkat } \\
\text { Pengangguran }^{1)}\end{array}$ & \multicolumn{4}{|c|}{$\begin{array}{l}\text { - Laju pertumbuhan penduduk yang rendah } \\
\text { dimanfaatkan untuk mencegah alih fungsi lahan, } \\
\text { tekanan penduduk terhadap lahan DTA dan } \\
\text { tingkat pengangguran yang tinggi }\end{array}$} & \multicolumn{4}{|c|}{$\begin{array}{l}\text { - Mengendalikan alih fungsi lahan agar luas hutan } \\
\text { meningkat dan lahan kritis semakin menurun }\end{array}$} \\
\hline
\end{tabular}

Pilihan strategi dalam matriks di atas belum menunjukkan prioritas strategi yang perlu dilakukan dalam menunjang keberlanjutan DTA Bendung Ciliman. Prioritas strategi didapatkan melalui 2 tahapan yaitu dilihat dari sensitifitas hasil analisis MDS dan hasil posisi kuadran analisis SWOT. Prioritas strategi pertama ada pada kuadran S-O hasil analisis SWOT dimana didalamnya terdapat 2 atribut sensitif MDS yaitu tingkat layanan pendidikan dan jumlah koperasi. Sehingga menghasilkan prioritas strategi sebagai berikut:

1. Memanfaatkan laju pertumbuhan penduduk untuk meningkatkan jumlah koperasi

Laju pertumbuhan penduduk di DTA Bendung Ciliman yang terdiri atas 3 kecamatan yaitu Kecamatan Banjarsari, Kecamatan Cirinten, dan Kecamatan Gunung Kencana dapat dikatakan rendah yaitu sebesar $0.83 \%$, dibandingkan dengan laju pertumbuhan penduduk Provinsi Banten dan nasional yang masing-masing sebesar $2.11 \%$ dan $1.64 \%$. Sehingga dapat dimanfaatkan sebagai kekuatan untuk meningkatkan kesejahteraan penduduk di daerah tersebut melalui peningkatan jumlah koperasi. Rendahnya pertumbuhan penduduk menyebabkan kebutuhan ekonomi masyarakat di daerah tangkapan air menjadi rendah sehingga dapat dialihkan pada peningkatan jumlah koperasi di DTA Bendung Ciliman. Jumlah koperasi merupakan atribut sensitif hasil analisis MDS sehingga perlu dimasukkan dalam prioritas strategi konservasi DTA Bendung Ciliman. Menurut data dari Badan Pusat Statistik Kabupaten Lebak, jumlah koperasi di DTA Bendung Ciliman masih sangat sedikit hanya terdapat 3 koperasi. Koperasi tersebut hanya berada pada Kecamatan Gunung Kencana yang terdiri dari 2 KUD dan 1 non KUD.

2. Memanfaatkan tutupan vegetasi untuk meningkatkan jumlah koperasi

Berdasarkan kriteria Permenhut no P.61 tahun 2014, tutupan vegetasi di DTA Bendung Ciliman dapat dikatakan cukup tinggi yaitu sebesar 68.6\%. Tutupan vegetasi tersebut terdiri dari hutan $3.41 \%$, kebun $49.87 \%$, 
dan semak belukar $28.99 \%$. Luasan vegetasi yang tinggi dapat dimanfaatkan oleh masyarakat sekitar hutan untuk meningkatkan nilai ekonomi hutan. Nilai ekonomi hutan yang dapat dimanfaatkan antara lain untuk produksi biomassa, sarana rekreasi, pemanfaatan tumbuhan obat, dan lian-lain (Munasinghe, 1993). Oleh karena itu, masyarakat dapat membentuk koperasi yang bergerak di bidang kehutanan dan pertanian untuk meningkatkan jumlah koperasi di DTA Bendung Ciliman. Pengembangan koperasi di bidang pertanian sudah dilakukan oleh Kementerian Pertanian khususnya Direktorat Jenderal Prasarana dan Sarana Pertanian melalui Program Korporasi Berbasis Mekanisasi (PKBM), tetapi perlu dikembangkan pada lokasi-lokasi yang memiliki potensi lahan pertanian yang lebih baik. Pengembangan koperasi di bidang kehutanan juga sudah dilakukan oleh Kementerian Lingkungan Hidup dan Kehutanan melalui Program Perhutanan Sosial yang merupakan program pengelolaan hutan lestari yang dilaksanakan dalam kawasan hutan negara atau hutan hak/adat yang dilaksanakan masyarakat setempat untuk meningkatkan kesejahteraannya. Pengembangan koperasi juga perlu bantuan pemerintah khususnya pada sektor kemitraan dan investasi agar keberlanjutan koperasi dapat terjamin.

3. Memanfaatkan tingkat layanan pendidikan yang baik untuk meningkatkan luas hutan, penggunaan lahan, dan lahan kritis

Tingkat layanan pendidikan merupakan atribut sensitif hasil analisis MDS. Tingkat layanan pendidikan di DTA Bendung Ciliman dilihat dari jumlah sekolah tingkat SD sampai dengan SMA/SMK dibandingkan dengan jumlah punduduk usia sekolah tingkat tersebut, dihasilkan tingkat pendidikan sebesar $0.61 \%$. Tingkat layanan pendidikan tersebut lebih tinggi dibandingkan dengan tingkat layanan pendidikan di Kabupaten Lebak dan Provinsi Banten yang masing-masing sebesar $0.54 \%$ dan $0.41 \%$. Tingkat layanan pendidikan yang baik dapat dimanfaatkan untuk mengadakan kurikulum yang mempelajari tentang pentingnya daerah tangkapan air ataupun daerah aliran sungai agar kondisi ekologi yang sensitif hasil dari analisis MDS seperti luas hutan dan lahan kritis dapat terjaga. Pengetahuan masyarakat yang berada di DTA Bendung Ciliman juga perlu ditingkatkan khususnya tentang peraturan-peraturan pemerintah yaitu tentang penataan ruang. Rencana Tata Ruang Wilayah (RTRW) Kabupaten Lebak mengatur tentang luasan hutan yang tidak boleh kurang dari 30\% dari luas DAS.

4. Memanfaatkan laju pertumbuhan penduduk untuk meningkatkan NTP dan mengurangi pengangguran

Nilai tukar pertani (NTP) dan tingkat pengangguran merupakan atribut sensitif hasil analisis MDS sehingga perlu dimasukkan dalam strategi SWOT untuk meningkatkan keberlanjutannya pada dimensi ekonomi dengan memanfaatkan laju pertumbuhan penduduk. Rendahnya pertumbuhan penduduk menyebabkan kebutuhan ekonomi masyarakat di daerah tangkapan air menjadi rendah, sehingga dapat dialihkan pada kesejahteraan masyarakat sehingga NTP dapat ditingkatkan dan mengurangi pengangguran. agar daya beli masyarakat dapat ditingkatkan, sehingga produk-produk hasil pertanian dapat terserap seluruhnya. Kebutuhan ekonomi lainnya juga dapat dialihkan pada bantuan-bantuan kepada petani agar biaya produksi hasil pertanian menurun, sehingga NTP di daerah tangkapan air dapat meningkat. Kebutuhan ekonomi masyarakat juga dapat dialihkan pada peningkatan jumlah lapangan pekerjaan melalui pembukaan lembaga-lembaga koperasi ataupun memberikan modal usaha kepada masyarakat. Pembukaan lembaga koperasi dan pemberian modal usaha juga dibarengi dengan peningkatan program pendidikan dan pelatihan kepada masyarakat agar koperasi dan usaha masyarakat tersebut dapat berkelanjutan.

\section{SIMPULAN}

Kondisi existing ekologi dan ekonomi di DTA Bendung Ciliman masih cukup buruk dilihat dari luas hutan di DTA Bendung Ciliman masih sangat kecil hanya sebesar 3.41\% dan koefisien rejim aliran yang tinggi yaitu sebesar 68.41. Kondisi ekonomi yang buruk dilihat dari jumlah koperasi yang masih sedikit dan kesejahteraan penduduk yang rendah. Berdasarkan hasil integrasi analisis MDS dan SWOT, menunjukkan status keberlanjutan DTA berada di ambang batas keberlanjutan yaitu sebesar 52.52. Untuk mempertahankan keberlanjutan tersebut, maka atribut sensitif (leverage) dijadikan strategi dalam analisis SWOT sehingga 
menghasilkan strategi yang perlu dilakukan yaitu: 1) Memanfaatkan laju pertumbuhan penduduk untuk meningkatkan jumlah koperasi; 2) Memanfaatkan tutupan vegetasi untuk meningkatkan jumlah koperasi; 3) Memanfaatkan tingkat layanan pendidikan yang baik untuk meningkatkan luas hutan, penggunaan lahan, dan lahan kritis; 4) Memanfaatkan laju pertumbuhan penduduk untuk meningkatkan NTP dan mengurangi pengangguran.

\section{DAFTAR PUSTAKA}

[BLH] Balai Lingkungan Hidup Daerah Provinsi Banten. 2015. Studi Penutupan Lahan DAS Ciliman. Banten (ID): BLH Daerah Provinsi Banten.

[BPS] Badan Pusat Statistik Provinsi Banten. 2017. Banten Dalam Angka 2016. Banten (ID): Badan Pusat Statistik.

[BPS] Badan Pusat Statistik Kabupaten Lebak. 2017. Kabupaten Lebak Dalam Angka 2016. Lebak (ID): Badan Pusat Statistik.

[BPS] Badan Pusat Statistik Kabupaten Lebak. 2017. Kecamatan Banjarsari Dalam Angka 2016. Lebak (ID): Badan Pusat Statistik.

[BPS] Badan Pusat Statistik Kabupaten Lebak. 2017. Kecamatan Cirinten Dalam Angka 2016. Lebak (ID): Badan Pusat Statistik.

[BPS] Badan Pusat Statistik Kabupaten Lebak. 2017. Kecamatan Gunung Kencana Dalam Angka 2016. Lebak (ID): Badan Pusat Statistik.

[Dinas PUPR] Dinas Sumber Daya Air dan Pemukiman Provinsi Banten. 2016. Studi Komprehensif Pengendalian Daya Rusak Air pada DAS Ciliman. Banten (ID): Dinas Sumber Daya Air dan Pemukiman Provinsi Banten.

[KLHK] Kementerian Lingkungan Hidup dan Kehutanan. 2014. Peraturan Menteri Lingkungan Hidup dan Kehutanan Nomor: P.61/Menhut-II/2014 tentang Monitoring dan Evaluasi Pengelolaan Daerah Aliran Sungai. Jakarta (ID): KLHK.

Asdak. 2010. Hidrologi dan Pengelolaan Daerah Aliran Sungai. Yogyakarta (ID): Gadjah Mada University Press.

Kavanagh P. 2001. Rapid Appraisal of Fisheries (RAPFISH) Project. Vancouver (US): Fisheries Center, University of British Colombia.

Munasinghe M. 1993. Environmental Economics and Sustainable Development. Ed ke-3. Washington (US): World Bank Environment.

Pawitan H. 2006. Perubahan Penggunaan Lahan dan Pengaruhnya Terhadap Hidrologi DAS. Bogor (ID): Laboratorium Hidrometeorologi, FMIPA, IPB.

Rangkuti F. 2014. Analisis SWOT: Teknik Membedah Kasus Bisnis. Ed ke-18. Jakarta (ID): PT Gramedia Pustaka Utama.

Williams ID, Walsh WJ, Schroeder RE, Friedlander AM. 2008. Assessing the importance of fishing impacts on Hawaiian coral reef fish assemblages along regional-scale human population gradients. $J$ Environmental Conservation. 35(3): 261-272.

Zagonari F. 2008. Integrated coastal management: Top-down vs community based approaches. $J$ of Environmental Management. 88(4): 796-804. 